Synt hesi s of 1-hydr oxyyohi mbi ne and its novel skel et al rear rangement react i on i nt o oxi ndol e der i vat i ves

\begin{tabular}{|l|l|}
\hline 著者 & Sonei Nasanor i, Noguchi Koi chi , Yamada Fumi o \\
\hline $\begin{array}{l}\text { j our nal or } \\
\text { publ i cat i on t i t l e }\end{array}$ & Het er ocycl es \\
\hline vol une & 55 \\
\hline number & 7 \\
\hline page r ange & $1237-1240$ \\
\hline year & 2001- 07- 01 \\
\hline URL & ht t p: //hdl . handl e. net /2297/4368 \\
\hline
\end{tabular}




\title{
SYNTHESIS OF 1-HYDROXYYOHIMBINE AND ITS NOVEL SKELETAL REARRANGEMENT REACTION INTO OXINDOLE DERIVATIVES 1
}

\author{
Masanori Somei, ${ }^{*}$ Koichi Noguchi, and Fumio Yamada \\ Faculty of Pharmaceutical Sciences, Kanazawa University, \\ 13-1 Takara-machi, Kanazawa 920-0934, Japan
}

\begin{abstract}
Hydroxyyohimbine was prepared for the first time. Its skeletal rearrangement reaction either directly into 2-oxindole or into 3-oxindole derivatives by a series of reaction is reported. 1-Hydroxyyohimbine and some of its derivatives showed potent $\alpha 2$ blocking activity.
\end{abstract}

We have supposed $2 \mathrm{a}$ that 1 -hydroxyindoles $(\mathbf{A})$ undergo the rearrangement reaction as illustrated in Scheme 1 to provide 2-oxi- (B) and/or 3-oxindoles (C) regarding their possible role in biological processes. 2 In our continuing efforts to realize it chemically, we have succeeded in finding such example that $1,2,3,4$ tetrahydro-9-hydroxy- $\beta$-carbolines (D) tranform to 3,3-disubstituted 2-oxindoles ${ }^{3}$ (E) under acidic conditions. As a result, whether the same type of rearrangement occurs in the cases of more complex natural products has been an interesting and important subject for us to verify our "1-Hydroxyindole Hypotheses". 2 Now, we wish to report that the predicted rearrangement actually occurs in the case of yohimbine alkaloids.

\section{Scheme 1}

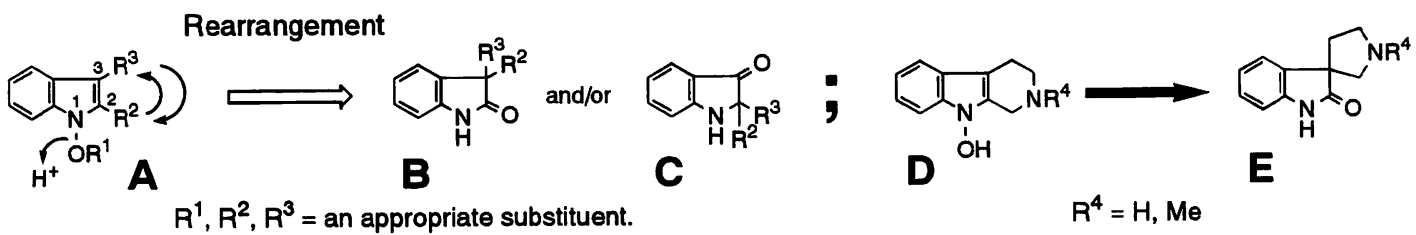

First, we needed a novel 1-hydroxyyohimbine (1). According to the reported procedure, ${ }^{4}$ we tried the reduction of yohimbine (2) with $\mathrm{NaBH}_{3} \mathrm{CN}$ in TFA to give $2 \beta, 7 \beta-(3)$ and $2 \alpha, 7 \alpha$-dihydroyohimbine (4) in 9 and $89 \%$ yields, respectively. Subsequent application of our $\mathrm{Na}_{2} \mathrm{WO}_{4} \cdot 2 \mathrm{H}_{2} \mathrm{O}$ and $30 \% \mathrm{H}_{2} \mathrm{O}_{2}$ method 5 to 4 afforded the desired 1 for the first time in $86 \%$ yield as stable crystals.

The formation of by-product (3) in the first step is not only the cause of lowering the yield of 4 but also a troublesome problem for its separation. Therefore, in order to improve the process, we explored the reduction of yohimbine hydrochloride $(2 \cdot \mathbf{H C l})$ as a substrate with $\mathrm{NaBH}_{3} \mathrm{CN}$ in TFA and discovered the stereoselective production of 4 in an quantitative yield without any detectable amount of 3 . Consequently, by conducting the two procedures sequentially, 1 was readily available from $2 \cdot \mathbf{H C l}$ in $86 \%$ yield. 
Syntheses of some derivatives of 1 were examined with an aim to develop biologically active substances. Thus, methylation with $\mathrm{CH}_{2} \mathrm{~N}_{2}$ afforded 1-methoxy compound 6 (5) in $77 \%$ yield. Utilizing $\mathrm{K}_{2} \mathrm{CO}_{3}$ as a base in DMF, allyl bromide, butyl iodide, and p-nitrobenzyl bromide reacted successfully with 1 to afford 6, 7, and 8 in 93, 99, and 90\% yields, respectively. These compounds including 1 itself showed potent $\alpha 2$ blocking activity and the details will be reported in due course.



Table 1

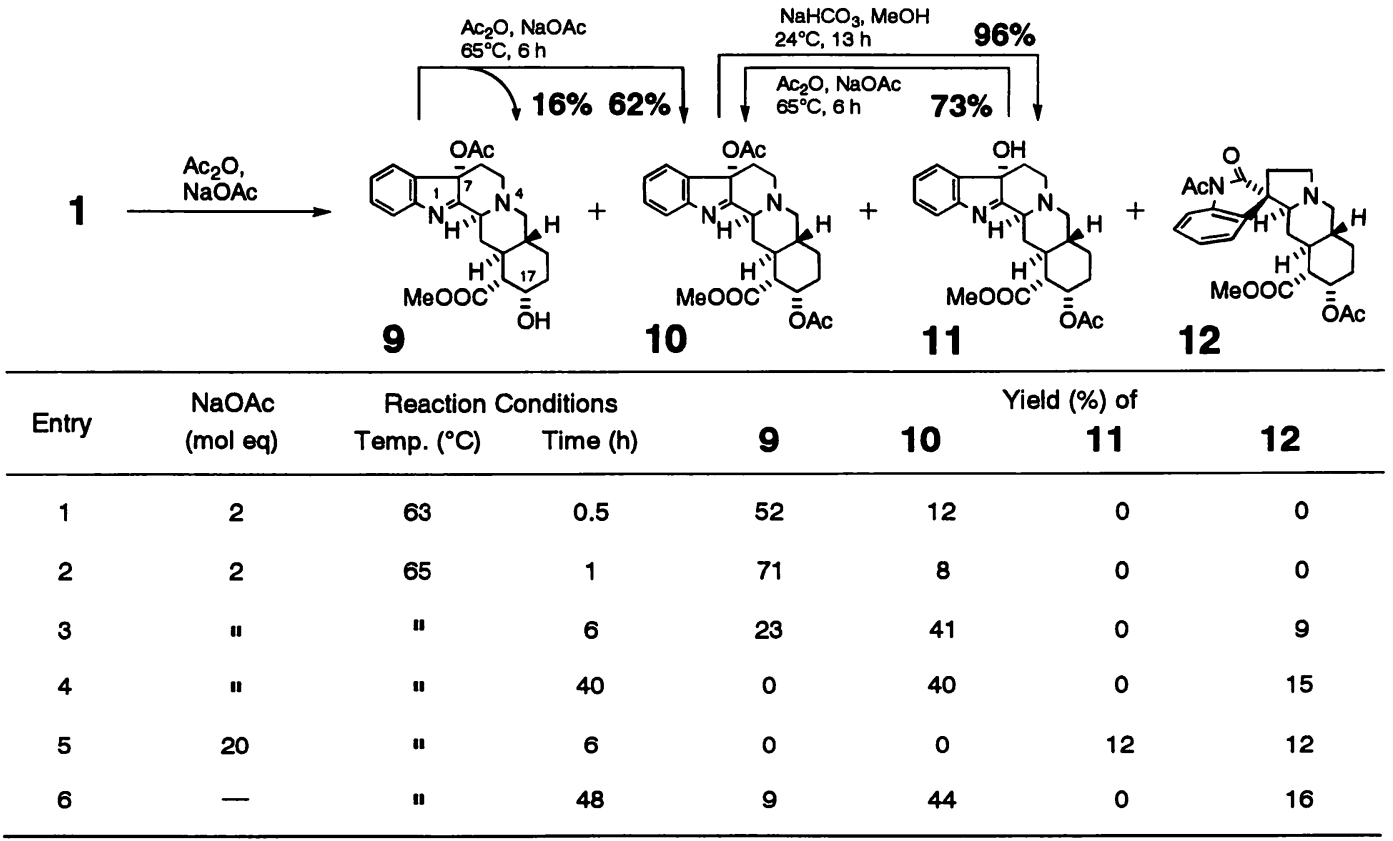


With 1 in hand, we next tried its reaction with $\mathrm{Ac}_{2} \mathrm{O}$ in the presence of $\mathrm{NaOAc}$ which is a suitable condition for promoting rearrangement ${ }^{7}$ of 1 -hydroxy group and the results are summarized in Table 1 . As can be seen from the Table, possible four products were produced stereoselectively such as $7 \alpha$-acetoxy- 8 (9), $7 \alpha$-acetoxy-17-O-acetyl- (10), 17-O-acetyl-7 $\alpha$-hydroxyyohimbines (11), and the predicted 2-oxindole (12). The rearrangement of 1 -acetoxy group to $7 \alpha$-position was best achieved under the reaction conditions described in Entry 2 providing $9(71 \%)$ and $10(8 \%)$. As the reaction time became longer (Entries 1-4), the yield of 9 decreased, while the yield of 10 increased. In the cases of Entries 3 and 4, the expected formation of 2-oxindole (12) was observed. Use of excess amount of NaOAc made the reaction dirty and as a result total yield of prod- ucts (11 and 12) decreased (Entry 5). The slight improvement in the yield of $12(16 \%)$ was observed by. carrying out the reaction without using NaOAc, together with 9 and 10 in the respective yields of 9 and $44 \%$ (Entry 6).

Figure 1. X-Ray Single Crystallographic Analyses

ORTEP Drawing of $\mathbf{1 0}$

$$
(R=0.030)
$$
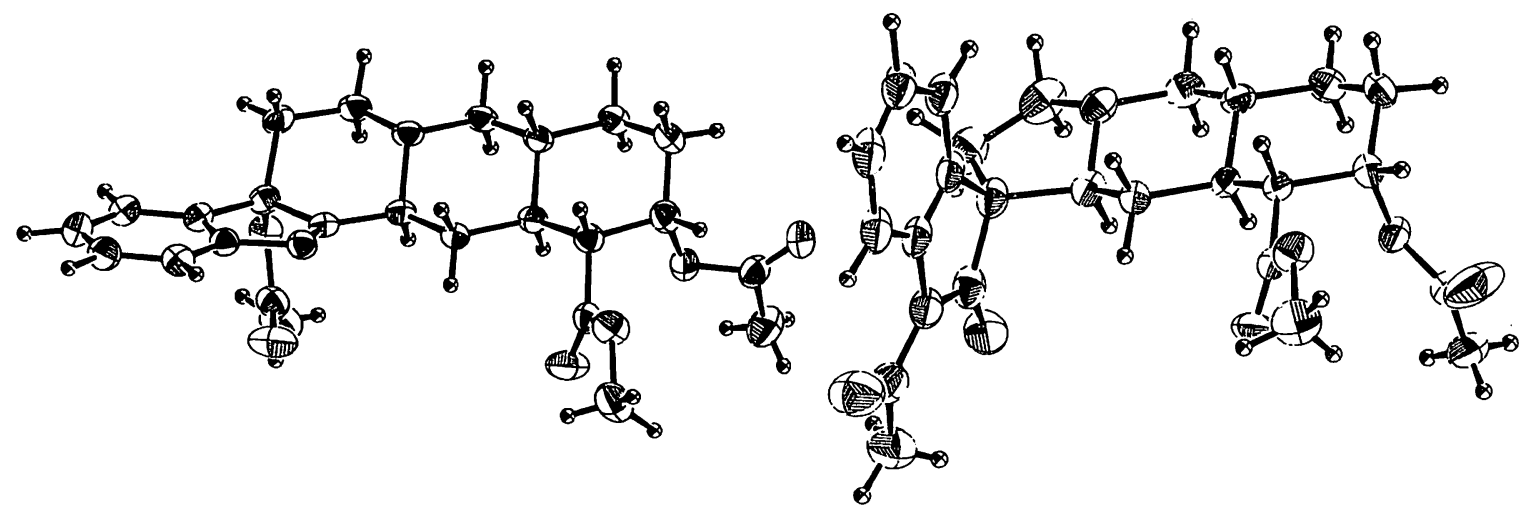

Scheme 3

9

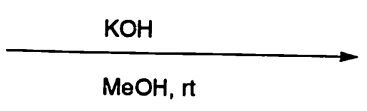

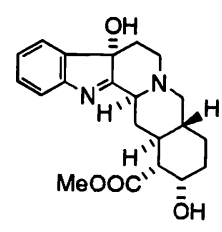

13

\section{ORTEP Drawing of 12}

$$
(R=0.031)
$$


$\mathrm{NaHCO}_{3}$ in $\mathrm{MeOH}$ at room temperature.

On the other hand, a facile rearrangement of 9 to spiroindoxyl compound $8 \mathrm{a}$ ( 3 -oxindole, $8 \mathrm{~b} 14$ ) was already repoted by Finch and co-workers $8 \mathrm{c}$ through 13 by the hydrolysis of $7 \alpha$-acetoxy group, followed by alkaline treatment (Scheme 3). Therefore, we have succeeded in realizing the skeletal rearrangement of 1 into both 2-oxi- and 3-oxindole derivatives as predicted. ${ }^{2}$ Attempts to improve their yields, preparations of various kinds of 1-hydroxyyohimbine derivatives, and their biological evaluations are currently in progress.

\section{ACKNOWLEDGMENT}

The authors express their cordial gratitude to Prof. H. Shigenobu (Toho University School of Pharmaceutical Science) for biological evaluations.

\section{REFERENCES AND NOTES}

1. a) This is Part 106 of a series entitled “The Chemistry of Indoles". b) Part 105: K. Yamada, T. Kawasaki, T. Fujita, and M. Somei, Heterocycles, 2001, 55, 1151. All new compounds gave satisfactory spectral and elemental analysis data. $1, \mathrm{mp} 224-226^{\circ} \mathrm{C}$ (decomp); $5, \mathrm{mp} 201-203^{\circ} \mathrm{C}$ (lit. $\left.{ }^{6} \mathrm{mp} 198-201^{\circ} \mathrm{C}\right) ; 6, \mathrm{mp} 126.0-128.5^{\circ} \mathrm{C}$ (decomp); 7, mp $150-152^{\circ} \mathrm{C}$ (decomp); 8, mp 148 $-149^{\circ} \mathrm{C}$ (decomp); 9, mp $120-122^{\circ} \mathrm{C}$ (lit. $\left.{ }^{8 \mathrm{~b}} \mathrm{mp} 123-124^{\circ} \mathrm{C}\right) ; 10, \mathrm{mp} 190-191^{\circ} \mathrm{C} ; 11, \mathrm{mp} 193-$ $195^{\circ} \mathrm{C}$ (decomp); 12, $\mathrm{mp} 213-215^{\circ} \mathrm{C}$ (decomp).

2. a) Review; M. Somei, J. Synth. Org. Chem. Jpn., 1991, 49, 205; b) M. Somei and M. Natsume, Tetrahedron Lett., 1973, 2451; c) M. Somei and Y. Fukui, Heterocycles, 1993, 36, 1859; c) Review; M. Somei, ibid., 1999, 50, 1157 and references cited therein.

3. M. Somei, K. Noguchi, R. Yamagami, Y. Kawada, K. Yamada, and F. Yamada, Heterocycles, 2000, 53, 7 and references cited therein.

4. J. Le Men, L. Le Men-Oliver, J. Levy, M. C. Levy-Appert-Colin, and J. Hannart, Ger. Offen. 2,410,651 (Cl. C07d) [Chem. Abstr., 1975, 82, 43640u]. See also reference 6.

5. M. Somei and T. Kawasaki, Heterocycles, 1989, 29, 1251; M. Somei, T. Kawasaki, K. Shimizu, Y. Fukui, and T. Ohta, Chem. Pharm. Bull., 1991, 39, 1905.

6. H. Takayama, N. Seki, M. Kitajima, N. Aimi, H. Seki, and S. Sakai, Heterocycles, 1992, 33, 121.

7. M. Somei, T. Kawasaki, Y. Fukui, F. Yamada, T. Kobayashi, H. Aoyama, and D. Shinmyo, Heterocycles, 1992, 34, 1877.

8. a) B. Witkop and J. B. Patrick, J. Am. Chem. Soc., 1951, 73, 2188. b) H. Takayama, M. kurihara, S. Subhadhirasakul, M. Kitajima, N. Aimi, and S. Sakai, Heterocycles, 1996, 42, 87. c) N. Finch, C. W. Gemenden, I. H.-C. Hsu, and W. I. Taylor, J. Am. Chem. Soc., 1963, 85, 1520; N. Finch, C. W. Gemenden, I. H.-C. Hsu, A. Kerr, G. A. Sim, and W. I. Taylor, ibid., 1965, 87, 2229. 